\title{
Redrawing Hot Spots of Crime in Dallas, Texas ${ }^{*}$
}

Andrew P. Wheeler ${ }^{1, * *}$, Sydney Reuter ${ }^{2}$

*Data and code to replicate the findings can be obtained from

https://www.dropbox.com/sh/kcask6pinaaaz4v/AAC4CXk6NzUweyld2n4OznzWa?dl=0

**Corresponding author, email: apwheele@gmail.com

1. Health Management Systems

2. School of Economic, Political, and Policy Sciences - Program in Criminology \& Criminal Justice

Andrew P. Wheeler, PhD, is a Data Scientist at Health Management Systems. This work does not represent the views of HMS.

Sydney Reuter is a Masters student in the Criminology program at UT Dallas. 
Title: Redrawing hot spots of crime in Dallas, Texas

\begin{abstract}
In this work we evaluate the predictive capability of identifying long term, micro place hot spots in Dallas, Texas. We create hot spots using a hierarchical clustering algorithm, using law enforcement cost of crime estimates as weights. Relative to the much larger current hot spot areas defined by the Dallas Police Department, our identified hot spots are much smaller (under 3 square miles), and capture crime harm at a higher density per the Predictive Accuracy Index statistic. We also show that the hierarchical clustering algorithm captures a wide array of hot spot types; some one or two addresses, some street segments, and others an agglomeration of larger areas. This suggests identifying hot spots based on a specific unit of aggregation (e.g. addresses, street segments), may be less efficient than using a hierarchical clustering technique in practice.
\end{abstract}

Keywords: hot-spots, clustering, crime-harm, prediction, cost-benefit-analysis

Code and data to reproduce the analysis can be downloaded from

https://www.dropbox.com/sh/kcask6pinaaaz4v/AAC4CXk6NzUweyld2n4OznzWa?dl=0

\title{
Introduction
}

While targeting police resources at micro place hot spots has been one of the most successful policing interventions to reduce crime (Braga, Papachristos, \& Hureau, 2014), it is still an open question as to how to construct those hot spots. Using open crime data from Dallas, Texas, this article provides an example of constructing long term micro place hot spots. Using historical data to identify hot spots of crime, we show how our identified clusters capture more crime harm in a smaller spatial extent than current Dallas hot spot areas on future crimes.

While there are a plethora of prior articles examining the predictive ability of different hot spot methods (Chainey, Thompson, \& Uhlig, 2008; Drawve, 2016; Levine, 2008; Van Patten, McKeldin-Conor, \& Cox, 2009), there are three novel contributions of this work. First, we illustrate the use of a hierarchical clustering technique, DBSCAN (Campello, 2013), to formulate different contiguous hot spot areas. A point of contention in prior work is the correct spatial unit of analysis to conduct analysis on. For example, several scholars often suggest street segments (Rosser et al., 2017; Weisburd et al., 2004), some suggest street segments and intersections (Braga, Papachristos, \& Hureau, 2010; Wheeler, Worden, \& McLean, 2016), and others have suggested targeting specific addresses (Eck, Clarke, \& Guerette, 2007; Lee \& Eck, 2019; Sherman, Gartin, \& Buerger, 1989). Using a hierarchical clustering technique allows one to avoid needing to specify such a spatial unit of analysis up front, and can be used on address based crime data to identify a reasonable resolution for a particular hot spot. In the micro place hot spots we identify, we subsequently show some are one or two addresses clustered together, others are a street segment, and others are an agglomeration of several nearby street segments.

The second novel contribution of this work is to construct hot spots using weighted harm scores (Ignatans \& Pease, 2016; Ratcliffe 2015; Sherman, Neyroud, \& Neyroud, 2016; Macbeth $\&$ Ariel, 2017). To do this, we use average Uniform Crime Report (UCR) cost of crime estimates 
(per law enforcement) for Texas as weights in the DBSCAN algorithm (Hunt, Saunders, \& Kilmer, 2019). This provides more interpretable hot spot summaries in terms of direct cost of crime estimates relevant to police departments. These cost of crime estimates can be used to provide more actionable information in terms of cost-benefit analysis for police departments when planning a hot spots policing strategy.

The third novel contribution of the study is to evaluate the predictive accuracy of our identified crime weighted hot spots using historical data to predict future crimes. While prior

work has mapped harm spots (Curtis-Ham \& Walton, 2017; Fenimore, 2019; Norton et al., 2018; Weinborn et al., 2018), the majority of that work has simply focused on crime concentration, and has not assessed the predictive accuracy of a technique to create such harmspots (for an exception, see Macbeth \& Ariel, 2017). Additionally, most of that work has mapped harm spots at a specific pre-chosen unit of analysis (Curtis-Ham \& Walton, 2017; Mitchell, 2019; Norton et al., 2018; Weinborn et al., 2018, for an exception see Fenimore, 2019 who used weighted kernel density estimates). We show here in our constructed hot spot areas there is no spatial unit of analysis that would consistently cover the same areas we identified.

The study area of Dallas was chosen for one main reason. They have historically identified long term hot spot areas, Target Area Action Grids (TAAG) (Ferguson, 2017; Worrall $\&$ Wheeler, 2019). These hot spot areas on their face do not conform with contemporary advice on targeting micro place hot spots of crime. TAAG areas cover 64 square miles of Dallas, around $20 \%$ of the city. We show that TAAG areas capture around $60 \%$ of the total crime harm in the city. Weisburd's law of crime concentration states that approximately $5 \%$ of the places within a city typically capture around $50 \%$ of the total amount of crime (Weisburd, 2015). Thus it suggests one can identify a much smaller subset of the city and capture crime at a much higher density.

A common statistic used to evaluate crime forecasts is the Predictive Accuracy Index (PAI) (Chainey et al., 2008). The PAI is simply the ratio of the proportion of crime captured for the numerator and the percent of the area covered by the prediction in the denominator. A simple extension this statistic is to consider not just the proportion of total crimes captured, but the total cost of crime captured. We show that current TAAG areas in Dallas have cost-of-crime PAI's of around 3 (60\% crime harm/20\% of area of city), while Weisburd's law of crime concentration suggests a reasonable baseline for PAI statistics should be 10 (50\% of crime/5\% of the area). Our identified hot spot areas are much smaller, cover less than $1 \%$ of the area of the city (around 2.5 square miles), capture $12 \%$ of the total harm in the city, and subsequently have a combined PAI of 16 .

\section{Literature Review}

\section{Creating Hot Spots of Crime}

Work that identified that crime clusters at small locations, such as specific addresses (Sherman, Gartin, \& Buerger, 1989), or street segments (Weisburd et al., 2004) was likely the innovation that spurred subsequent work on hot spots policing (Braga, Papachristos, \& Hureau, 2014; Lum, Koper, \& Telep, 2011). This innovation was particularly important given the lack of prior successes of police interventions to reduce crime (Bayley, 1994). In retrospect, those poor 
results are likely attributable to police targeting of much larger areas (Larson, 1975), which has been consistently shown to be less successful than targeting micro place hot spots (Lum, Koper, $\&$ Telep, 2011). However, despite the popularity of hot spots policing, there is not a single, unanimous definition of what constitutes a hot spot of crime (Taylor, 2015).

According to Haberman (2017), there are several different ways to identify hot spots. Before beginning, the size of the hot spot areas needs to be established. This can range from a large police beat, to a smaller grid area, and even to an even smaller microplace consisting of an intersection or street segment. It is important to then determine the criteria that may qualify an area as a hot spot. A common method includes the establishment of a minimum number of crimes that must have occurred in that area. Separately, selecting the locations with the highest number of crimes after rank-ordering the areas can be used to establish hot spots. Finally, spatial statistics may be used to identify clusters of crime, therefore revealing hot spots. Utilizing one of these methods, most researchers have identified hot spots of all crime within an urban area, while others have focused on a specific type of crime, such as violent or motor vehicle thefts (Haberman, 2017).

Sherman, Gartin, \& Buerger (1989) conducted a study on hot spots in Minneapolis which confirmed that relatively few areas produce the most calls to police. They found that half of all calls to police, were in only $3 \%$ of the places (addresses or intersections) within the city. Subsequent work by David Weisburd has stated a consistent law of crime concentration, that around $5 \%$ of the places in a city (where places are often defined as street segments) contain around 50\% of the crime (Weisburd, 2015). These approaches to identifying hot spots rely on one to pre-specify a particular unit of analysis (e.g. address, street segment, census block, patrol area, etc.), as well as a particular ranked threshold (e.g. the top 5\% of areas, or the top 10 areas) to set a cut-off for what constitutes a hot spot.

Chainey et al. (2008) identified a number of different mapping techniques that can be used to identity hot spots of crime that don't per se rely on a pre-defined unit of analysis or a simple threshold (e.g. top 5\% of the area). Examples include point mapping, clustering census areas, or kernel density estimation. The depiction of the hot spots on a map may vary depending of the level of concentration for the analysis. For example, if the focus is on streets, lines may be used, while if it was on areas/neighborhoods, shaded areas or gradients may be more appropriate (Eck et al., 2005). While these techniques potentially avoid relying on some arbitrary decisions (such as a spatial unit of analysis), they still rely on other arbitrary decisions, such as where to set the cut-off for a kernel density threshold to set the area for a hot spot. Frequently individuals use rules such as a $\mathrm{z}$-score above 3 to make such decisions for continuous predictions (Eck et al., 2005; Chainey et al., 2008; Drawve, 2016).

\section{Measuring Hot Spot Accuracy}

Given that how to draw hotspots is arbitrary, there has been extensive work on analyzing the accuracy of different hot spot mapping techniques (Chainey et al., 2008; Drawve, 2016; Flaxman et al., 2019; Lee et al., 2019; Mohler \& Porter, 2018).

One of the most common metrics, The Prediction Accuracy Index (PAI), is a technique used to calculating the overall accuracy of a hot spot, but take into account the size of the area predicted (Chainey et al., 2008; Drawve, 2016). For example, if one simply used the number of crimes captured in a predicted area, or similarly the hit rate of whether any crime occurred in a predicted area (for small temporal intervals), it would be unfair to compare a prediction that 
encompassed a much larger area than a smaller predicted hot spot. Using the hit rate, you would gain the best prediction by predicting the entire study area, which is ultimately not helpful in identifying small hot spots of crime.

The PAI metric however divides the total crimes captured in an identified hot spot with the size of the area being considered. The PAI formula can be written as:

$$
\frac{n / N}{a / A}=\frac{\% \text { Crime Captured }}{\% \text { Area of City }}=\mathrm{PAI}
$$

Where $n$ is the number of crimes captured in the identified hot spot, and $N$ is the total number of crimes in the entire study area, and this is the numerator for the PAI metric. The denominator is defined by $a$, the area of the hot spot, divided by $A$, the area of the entire city. As such, the metric reduces to the proportion of crimes captured in a hot spot for the numerator, and the proportion of the area considered in the denominator. For a simple example, Weisburd's law of crime concentration would suggest that $5 \%$ of the area of the city approximately captures $50 \%$ of the crime, which results in a PAI statistic of $0.5 / 0.05=10$.

It is important when evaluating this metric to use prospectively identified hot spots, and then use future crimes captured in those previously defined areas, e.g. create hot spots using 2016 data, and see how many crimes they capture in 2017 data. If one uses the same dataset to evaluate both, the accuracy of the method used to generate the hot spots will be greatly inflated (Berk, 2008).

Given we are interested in capturing weighted crime hot spots, we slightly adapt the PAI metric to take those weights into account. If one defines the weighted crime harm captured in a hot spot and the weighted crime harm in an entire city as below, where $w$ indicates the weight for a particular crime:

$$
\begin{aligned}
& \sum w \cdot n=v, \text { Weighted crime captured in hot spot } \\
& \sum w \cdot N=V, \text { Weighted crime in entire study area }
\end{aligned}
$$

We can then simply replace the numerator in the prior PAI formula with $v / V$, and have a value weighted $\mathrm{PAI}_{v}$ statistic.

$$
\frac{v / V}{a / A}=\frac{\% \text { Crime Harm Captured }}{\% \text { Area of City }}=\mathrm{PAI}_{v}
$$

This statistic is agnostic as to what constitutes the weights, which segues into our next section, how prior research has quantified crime harm weights to capture the notion that some crimes (e.g. violent interpersonal offenses) should take priority over lower level offenses (e.g. petty theft) when identifying areas for police departments to target.

\section{Calculating Crime Harm Scores}

Recognizing that all types of crime count the same amount towards the crime rate, although they differ in severity, Wolfgang (1985) conducted a survey to determine how the public perceived the severity of crimes. Each respondent was asked to compare and rate a number of crimes based on their description and details of the incident. These ratings were 
averaged to determine an overall score for each crime. Patterns could be seen in the scores from the survey, such as crimes involving multiple victims typically receiving a higher severity score than the same crimes with a fewer number of victims. Additionally, factors such as who the victim was, the amount of money involved in the crime, or the original intent of the individual, are all additional factors that were important to respondents when assigning severity scores.

Many researchers have begun developing harm indexes to more appropriately measure crime than by a count or rate within an area. Ratcliffe (2015) attempted to create a realistic measure of harm experienced by the community due to crime. Focusing in Philadelphia, each offense was assigned a score based on general guidelines to assist judges in assigning an appropriate penalty for guilty individuals. From here, the author believed the index should also include harms suffered by the community that were not included in the harm index since it focuses mainly on violent crime. This 'social harm perspective' extends to include poverty/cashloss, fraud, emotional harm, psychological harm, or sexual harm that may not be captured by serious crime numbers. The addition of other crime types, traffic accidents, and investigative activity/stops is more reflective of community harm and police responsibilities.

Sherman, Neyroud, \& Neyroud (2016) created the Cambridge Crime Harm Index, adopted for the UK from the previously created Crime Harm Index, where they rated the harm of each crime reported to the police. This measure excluded any proactive crime detections from the police department, as they could not reliably measure harm experienced by the population. Each crime was multiplied by the number of days in prison an offender would receive upon conviction of that crime.

The New Zealand Crime Harm Index is another example of measuring the harm of crime, in an effort to reallocate police resources more efficiently. Curtis-Ham \& Walton (2018) developed this measure as an alternative to the traditional Crime Harm Index, to be more specific with crimes in New Zealand. Although it takes a similar approach, the New Zealand Crime Harm Index uses the actual time served by the offender, to maintain proportionality between short and long sentences due to early releases and parole, account for Home Detention allotment, as well as account for the proportion of the sentence served.

The Western Australia Crime Harm Index was developed by House \& Neyroud (2018) to analyze harm levels among common offenses for first-time offenders. It was calculated by taking the median number of days sentenced for each first time offender in a sample of most common offense categories. Conditional community sentences and monetary penalties were additionally accounted for in termed of the equivalent number of prison days. The number of offenses for each category was multiplied by the median number of prison days sentenced per category. This created the Western Australia Crime Harm Index, which was found to have the potential to improve policing, as well as community safety in Western Australia.

Mapping crime harm spots can take many different forms. Weinborn, Ariel, Sherman, \& O'Dwyer (2017) identified the top 5\% of street segments (two standard deviations away from the mean) that accounted for the most crime in the city to be hotspots, and constructed weights based on a crime harm index centered around sentencing data. Curtis-Ham \& Walton (2017) used census units to determine which areas of New Zealand had the highest crime harm, specifically comparing the Crime Harm Index with the New Zealand Priority Locations Index. Norton, Ariel, Weinborn, \& O'Dwyer (2018) measured harm within street segments using the Crime Harm Index based on sentencing guidelines, and included results within three standard deviations of the mean. They identified the four most harmful offense categories (violence against persons, sexual offense, robbery and theft) to make up $80 \%$ of the harm within the 99 harm spots. 
Mitchell (2019) created the California Crime Harm Index using a measure of potential maximum prison days to evaluate the Sacramento Hot Spot Experiment in comparison with crime counts for the area. Fenimore (2019) used weighted kernel density estimates to show that while crime harm tended to be as concentrated as crime counts, crime clusters were in different areas than clusters with crime counts. This was due to violent crimes contributing more to the weights, which were based on sentencing guidelines or the prior severity scores based on the Wolfgang survey.

As opposed to using crime harm estimated via sentencing decisions, we take a different tact in this analysis; we use estimates of costs of crime relevant directly to a police department. Hunt, Saunders, and Kilmer (2019) chose to calculate crime specific variable cost estimates (for police departments) to aid in cost-benefit analysis. Using this type of data to construct hot spots, instead of focusing on sentencing guidelines and punishment, can directly relate to the benefits of reducing crime in that area that are directly realized by police. As they pointed out in the article, crimes that have the biggest costs often require the largest amount of manpower and time. Therefore, by reducing crime in those hot spot locations, the police department and city may be able to save money. This may be more helpful than analyzing hot spots based on sentencing guidelines, as a department may not have as much motivation to make a change based on this data, since they will not directly benefit, nor will it help them justify any upfront investment in targeting such hot spots.

For an example, if a hot spot had an estimate $\$ 1$ million dollars of harm over a year, and say a police department was interested in implementing a problem-oriented approach similar to that in the Lowell hot spot study (Braga \& Bond, 2008). In that study, the Lowell Police Department reduced various Part 1 crimes by around $20 \%$ to $40 \%$ relative to control areas. So if a police department can successfully replicate those same results, it would produce a savings of $\$ 200,000$ to $\$ 400,000$ dollars over a years time in resources not spent responding to crime in that area. One would not be able to make similar return on investment arguments to justify hot spots policing when using the prior crime harm indices based on sentencing decisions.

\section{Data and Methods}

Data used for the analysis all come from open data sources. Address level geocoded crime data is available from dallasopendata.com. For this analysis we use crime data from June2014 through December-2016 as the training dataset to draw historical hot spots, and then compare to test data from January-2017 through June-2018. While additional crime data was available at the time of writing, Dallas PD underwent a transition to NIBRS reporting, which subsequently caused various anomalies in the open data (such as a dramatic drop in thefts). The Dallas open data does not contain reported rapes, so the analysis here only examines the other Part 1 UCR index crimes; murder, aggravated assault, robbery, burglary, theft, and motorvehicle-theft. Crimes that were given the address of a Dallas PD station (or sub-station) were removed from the analysis.

For GIS files, we obtained 2017 TAAG hot spot areas from the same dallasopendata.com website. We obtained an outline of the city, as well as street centerlines, from https://gis.dallascityhall.com/shapefileDownload.aspx. There are a total of 54 TAAG areas. All geographic analysis was conducted using a local projection relevant for Dallas, a Lambert conformal conic projection centered in Texas. 
Although the main analysis uses area as the denominator for PAI calculations, street centerlines are used as an alternative denominator in place of area for PAI calculations in supplementary analysis (Drawve \& Wooditch, 2019). This supplementary analysis is available in the appendix, and largely mimics the same findings using area for PAI calculations that we focus on in the main analysis.

We eliminated several lochs from the city outline of Dallas proper, as including these areas would artificially increase PAI statistics, although they cannot reasonably have geocoded crime incidents occur within them (Wheeler \& Steenbeek, 2020). Figure 1 displays a map of Dallas proper, along with the 2017 Dallas PD identified TAAG areas. While these are 2017 areas, many are historically consistent, and are the same as those reported in Worrall \& Wheeler (2019).

For cost of crime estimates, we use the Texas specific estimates presented in Hunt, et al. (2019). Table 1 lists the descriptive statistics, as well as those cost of crime estimates per UCR offense. As the testing period is shorter (1.5 years vs 2.5 years), the total numbers of crimes are smaller. But on a per unit time scale, the overall crime counts between periods are largely comparable, so estimates based on the pre-data should be reasonable to forecast in time. This is especially the case since others have found micro place hot spots tend to be very stagnant over long periods of time (Andresen, Curman, \& Linning, 2017; Curman, Andresen, \& Brantingham, 2014; Weisburd et al., 2004; Wheeler, Worden, \& McLean, 2016).

\section{[INSERT TABLE 1 HERE AND FIGURE 1 HERE]}

There are two main methodological advances presented in the paper. One is the use of the DBSCAN (Density Based SCAN) clustering technique to create hotspots of crime (Campello et al., 2013). Being a hierarchical clustering technique, it is well suited to identify irregular shaped hotspots, such as runs along a street (Brantingham \& Brantingham, 1993; Grubesic, 2006).

While the contribution of illustrating DBSCAN is a minor change compared to other common hierarchical clustering techniques (Haberman, 2017), the main reason it was chosen is because it can easily incorporate weights into the clustering algorithm. ${ }^{1}$ Here we use cost of crime estimates as those weights when constructing hot spots. This is similar to past work that has used crime harm estimates to construct and evaluate hot spots (Macbeth \& Ariel, 2017; Ratcliffe, 2015).

For a brief description of how the clustering algorithm works, DBSCAN has two parameters that need to be chosen by the analysts; epsilon (the radius to which two points can ultimately be connected), and the minimum number of points (or here weighted points) to establish a cluster. These parameters are chosen here as 400 feet for epsilon, and $\$ 400,000$ for the total costs of crime within a hotspot. Four hundred feet was chosen as this is slightly less than the average street segment size in Dallas (Wheeler \& Steenbeek, 2020). So for an average length street segment in Dallas, if there were only crimes reported at either end, this technique would not link them together. Four hundred thousand dollars (in 2010 dollars) (Hunt et al., 2019) was

\footnotetext{
${ }^{1}$ This is not exclusive to DBSCAN, for example one could weight STAC clusters similarly (Block \& Block, 1995). However, we do believe hierarchical clustering techniques are the most useful for irregularly shaped crime clusters.
} 
chosen as a baseline harm spot value for the ad-hoc reason it tended to produce a total number of hot spots similar to the total number of TAAG areas.

$\$ 400,000$ is the minimum weight needed for the technique to return an identified cluster, it will ultimately identify areas with even more crime harm than that baseline. For a simplified example of how DBSCAN works, imagine you have two locations, A and B, that are 300 feet apart, and each have a total of $\$ 200,000$ in crime harm. Even though each location by itself does not meet the $\$ 400,000$ threshold, combined they do. Points A and B then form a core cluster. Points additionally within 400 feet from either A or B will additionally be considered inside the cluster, but unless all points within a radius of 400 feet exceed the $\$ 400,000$ in crime harm, they will not be considered a core point for the cluster.

We use the open source R statistical package to conduct the analysis, in particular the dbscan library, with cost estimates for crime as the weights (Hahsler, Piekenbrock, Doran, 2019). We create DBSCAN clusters based on the training dataset, and then buffer the core points within the clusters 400 feet to generate hot spot areas. We additionally merge any two clusters that this procedure results in overlaps, as well as remove any holes (areas in which it is entirely surrounded by a cluster). We then count the testing set number of crimes and their cost that fall within those hot spots, which provides an example of how such hot spots are used prospectively by police in practice (Berk, 2008). This procedure results in a total of 61 micro place clusters.

To evaluate the clusters, we then use the predictive accuracy index (PAI) to assess the accuracy of the hot spots. This common technique to measure accuracy (Chainey et al., 2008; Levine, 2008), and was used in the recent National Institute of Justice Forecasting challenge (Flaxman et al., 2019; Lee, O, \& Eck, 2019; Mohler \& Porter, 2018).

The PAI statistic is typically defined as the proportion of crimes captured in a hot spot area, divided by the proportion of the city the hot spot covers. For an example, if a particular set of identified hot spots covers $2 \%$ of the city, and the hot spots capture $10 \%$ of the total crime, that would result in a PAI of 20 . Here we make a simple modification to the PAI to accommodate cost of crime estimates, for the numerator we consider the total cost of crime captured, instead of simply the proportion of crime. So in our prior example, if there is a total of $\$ 1$ million dollars in crime harm in a city, and the same hot spot captures $\$ 200,000$ in crime harm (20\% of the total harm), using the same $2 \%$ of the area denominator, the PAI statistic would then be 40 . We evaluate both the total cumulative PAI identified by our DBSCAN clusters vs Dallas PD defined TAAG areas, as well as provide graphs and maps of individual identified hot spots.

\section{Results}

Table 2 displays the resulting citywide aggregate statistics, accumulating the entire TAAG and our identified DBSCAN hot spot areas. The total crime harm captured in the DBSCAN areas is just under 20 million dollars, which is $12 \%$ of the cost of crime in the city (over \$169 million dollars). Given that the DBSCAN areas cover less than 3 square miles (1\% of the city), this results in a PAI statistic of 16. Although the clusters were only fit on the cumulative proportions of each crime, overall they result in very similar PAI statistics when 
doing the (non-harm weighted) breakdowns for individual crime types, thus the results do not appear to be driving by a particular crime type.

While the TAAG hot spots capture a much larger proportion of crime and crime harm, they also cover a much larger area of the city. TAAG areas cover 65 square miles, $19 \%$ of the city. Overall TAAG's capture 54\% of the costs of crime in Dallas (over $\$ 92$ million dollars), resulting in a PAI of 2.9. Again the statistics only vary slightly when considering non-weighted crime counts, and are typically around a PAI of 3.

Figure 2 displays PAI statistics for individual TAAG and DBSCAN hot spot areas. The majority of the TAAG areas hover under a PAI of 5, whereas the DBSCAN areas have a much broader distribution. While the left tail of the DBSCAN hot spots falls short of the PAI over 10 ideal laid out in the introduction, 50 of the 61 DBSCAN clusters have a PAI of over 10. It happens that only three of the DBSCAN areas have a lower PAI (based on the cost of crime) than the highest PAI for TAAG areas.

\section{[INSERT TABLE 2 AND FIGURE 2 HERE]}

Figure 3 displays a screenshot of an interactive map we created to explore the areas, https://apwheele.github.io/MathPosts/HotSpotMap.html. The blue DBSCAN areas are all smaller than 0.2 square miles, whereas the red TAAG areas tend to be around 1 to 2 square miles. Like other work on hot spots at micro places (Weisburd et al., 2004), the DBSCAN clusters are spread throughout the city, although have several sub-clusters in different areas of the city. The majority (but not all) of DBSCAN areas are covered by TAAGs. This suggests many of the TAAG hot spots currently in place can simply be adjusted to focus on more specific places.

Another way to consider the size of a hot spot is to consider the length of the streets in the area, since that will more naturally define the area in which officers will be patrolling (Drawve \& Wooditch, 2019; Ratcliffe \& Sorg, 2017). For reference hot spot areas in terms of street length, in the Philadelphia policing tactics experiment, the hot spot areas tended to cover around 3 miles of streets (Groff et al., 2015). For the Philadelphia foot patrol experiment, the areas covered a total of 1.3 miles of street on average (Ratcliffe et al., 2011). The DBSCAN hot spots here on average cover just under 1 mile of street. Of the 61 DBSCAN hot spots, only 11 cover more than 1.3 miles of street length, and only one covers more than 3 miles of street length. For comparison the current TAAG areas cover on average 24 miles of streets. The smallest TAAG area in terms of street length coverage is 12 miles.

Figure 4 illustrates a more zoomed in focused screen shot of the same interactive map. The map provides tooltips when clicking on a blue DBSCAN area, and this provides a breakdown of the total crimes and the cost of crime captured in a particular DBSCAN area. The particular example shown, a cluster that runs along Scyene road and expands onto Saint Augustine road illustrates the utility of a hierarchical clustering technique. Clusters that rely on identifying elliptical shaped clusters would have a difficult time approximating that shape. This particular hot spot contains a Family Dollar store, a gas station, an elementary school, and several apartment complexes that all in toto contribute various crimes to this hotspot. One can see from the tool tip that the hot spot contains a variety of violent (26 aggravated assaults, 13 
robberies), as well as non-violent crimes (15 burglaries, 58 thefts, and 26 thefts of motorvehicles).

In terms of the question do hot spots tend to be a single address or a street segment, one can find examples to support either. Many of the clusters are 1 to 2 addresses, although this may in part be a function of the nature of the clustering algorithm. It can return a single address as a cluster if it happens to have more than $\$ 400,000$ dollars in harm in the training dataset. But if there are any addresses within 400 feet, even with a single crime, they will also be within the core cluster. One can also find examples that more closely approximate street segments, or several street segments nearby one another, which are a function of multiple addresses accumulating to reach that $\$ 400,000$ threshold.

\section{[INSERT FIGURE 3 AND FIGURE 4 HERE]}

Other exploratory data analysis did not reveal any obvious patterns to the identified hot spots. In particular we examined whether specific crime types tended to dominate the identified clusters. It could be since violent crimes have larger costs, the hot spots tend to be more violent on average. Or the opposite, since property crimes are much more prevalent, the hot spots are all dominated by thefts. Neither of these appeared to be the case - the majority of hot spots tended to have a wide distribution of crimes (although one could find some counter-examples dominated by violent or property crimes). This is contra to the work by Haberman (2017), who found hot spots of different crime types did not tend to overlap. This difference is perhaps a result of clustering on the combined crimes, instead of clustering crimes individually.

\section{Discussion}

The results of the analysis demonstrated what we believed at the onset - that Dallas PD could identify much smaller hot spots than the current TAAG areas in place and capture a much larger density of cost of crime per area. Like prior analysis of concentration of crime harm (Curtis-Ham \& Walton, 2017; Fenimore, 2019; Norton et al., 2018; Weinborn et al., 2018), we find micro places that have high values of crime harm in clusters. Additionally, we show that such micro places have long term stability in the harm, by showing that hot spots generated with historical data also capture high values of crime harm in the future (Norton et al., 2018). As such, our work is complimentary to many past analyses, and builds on a long standing literature of constructing and evaluating the predictive capability of hot spots clustering.

An additional finding of the work is that we identify a heterogenous set of areas that qualify as hot spots in our clustering algorithm. While much past work has either conducted analysis at a pre-specified unit of analysis, such as census areas (Curtis-Ham \& Walton, 2017), street segments (Norton et al., 2018), or specific addresses (O’Brien \& Winship, 2017), our approach identifies hot spots that do not nicely conform to any of those pre-specified units of analysis. Thus there is likely a potential to be more efficient in hot spot identification when using a solution that does not presume a specific structure for hot spots at the start. Although we note that any of these ranking approaches is likely better to the status quo of constructing hot spot areas based on personal intelligence (MacBeth \& Ariel, 2017). 
One strong limitation of the current analysis is that the definition of the cost of crime is not well agreed upon. While here we use the work of Hunt et al. (2019) that is mostly based on costs associated with police response to particular crimes, there is a wide array of ways to calculate the cost of crime (Domínguez \& Raphael, 2015). For example, a murder in this analysis is valuated at $\$ 124$ thousand dollars, whereas the value of a statistical life is often pegged at over one million dollars (Domínguez \& Raphael, 2015). This difference has to do with who bears the cost of the murder - for police it is mostly in terms of investigative time, whereas the cost is much more severe for the victims family (and infinite for the victim themselves). It may also be that crime prevented for individuals accumulate over a lifetime (Cohen \& Piquero, 2009), with failing to prevent crime resulting in long term negative externalities for various individuals. Finally, this does not consider additional considerations on allocating police resources, such as equity or preventing disproportionate minority contact with a hot spots policing approach (Wheeler, 2019). So while these cost of crimes estimates are relevant to police departments themselves, they may not be reasonable to the greater public when constructing a hot spots policing strategy.

Additionally this work relying on public data does not include rapes, and we also do not include Part 2 crimes, which are often considered public disorder crimes and additionally contribute to quality of life (Boggess \& Maskaly, 2014; Chappell, Monk-Turner, \& Payne, 2010; Ratcliffe, 2015). This is not a limitation for a police department applying such estimates internally, where they have access to all of the reported crime data, but even then non-reporting will cause such estimated cost of crime hot spots to be an underestimate of the cost of crime at particular places. So we believe that both of these biases likely underestimate the cost of crime that is occurring the hot spots we identify here. Given that the ultimate goal of identifying such hot spots is to prevent crime, these estimates may then be gross underestimates of the potential return on investment if Dallas PD targets crime in those identified areas. But that is also conditional on a hot spots policing strategy to be effective (Mitchell, 2019) - just placing hot spots on the map and not doing anything with that information will ultimately not reduce crime at those locations.

While this work focuses on long term crime forecasting, the application of using DBSCAN can potentially be extended to short term crime forecasting (Flaxman et al., 2019; Garnier, Caplan, \& Kennedy, 2018; Lee et al., 2019; Mohler et al. 2015; Ratcliffe et al., 2020). One approach that we believe may be fruitful is to use DBSCAN on the output of a predictive policing application applied at the address and intersection level to create homogenous areas to assign subsequent patrols (Deryol et al., 2016). Although raster based approaches to predictive policing are popular (Caplan \& Kennedy, 2011), these raster grids do not conform to the actual micro places and the street network that heavily influence crime (Groff, 2014; Rosser et al., 2017). While prior work has used the creation of the raster grid orientation and size of the grid cells as a hyperparameter when tuning machine learning models (Flaxman et al., 2019; Mohler \& Porter, 2018), one could similar use the DBSCAN parameters of epsilon and minimum weight in the same capacity to avoid relying in grid cells entirely. Such results are likely to result in more natural, contiguous hot spot areas to target. Such contiguous areas would not only require fewer resources to target (relative to separate hot spots not in the same area), but also would likely result in better police adherence when targeting those hot spots boundaries (Sorg et al., 2017). 
Given that errors associated with geocoding tend to be around 100 feet on average for crimes occurring outdoors (Wheeler, Gerell, \& Yoo, 2020), it likely does not make sense to cluster crimes within a smaller distance than that shown here, but it may be the case that one would identify more agglomerated areas if the epsilon clustering criteria was slightly larger, as one can see sub-clusters of the individual clustered hot spot areas in the resulting map in this analysis.

While this analysis is illustrative of how one might create cost-of-crime weighted hot spots, ultimately the optimal strategy to construct hot spots needs to entail what actions the police department is going to take within those hot spots (as well as functional constraints in the resources the police department can allocate). Historically Dallas PD has only generically stated TAAG area hot spots were formulated to predict areas of high crime (Ferguson, 2017). They have not articulated specific strategies they would undertake at said hot spots.

Take for example if Dallas PD knew they wanted to create foot or bike patrols for identified hot spots, and budgeted enough to assign 4 different officers on some regular basis. It is likely the case that only four officers cannot cover all 61 micro place hot spots identified in this analysis, but it would be easily possible for those officers to cover at least one of the micro place hot spots identified here, which are all under 0.2 square miles (Haberman \& Stiver, 2019; Ratcliffe \& Sorg, 2017). Given that such areas have a specific cost attached to them, it also provides more straightforward cost-benefit analysis if the Dallas PD wishes to advocate for more resources to be able to cover such hot spots, or to justify reallocating existing resources to cover such hot spots.

While those same officers could cover the existing TAAG areas, expanding the size of such hot spots will result in a more diffused intervention by the police, no matter what the intervention is (Larson, 1975). As such it is likely in Dallas PD's best interest to take a more vested approach to identify micro places, even if they do not have a specific plan for what to do in the current hot spots at the current time. It may be a police department wishes to generate such hot spots first, and then take a problem oriented approach to solving crimes in those areas (Braga et al., 1999). Given that targeted police interventions at large areas tend to be less successful than micro placed focused interventions (Lum, Koper, \& Telep, 2011), weighted cost-of-crime DBSCAN identified hot spots are a tool crime analysts for any police department should consider in formulating a hot spots policing strategy.

\section{References}

Andresen MA, Curman AS, Linning SJ (2017) The trajectories of crime at places: Understanding the patterns of disaggregated crime types. Journal of Quantitative Criminology 33: 427449.

Bayley DH (1994) Police for the Future. Studies in Crime and Public Policy.

Berk R (2008) Forecasting methods in crime and justice. Annual Review of Law and Social Sciences 4: 219-238. 
Block RL, Block CR (1995) Space, place and crime: Hot spot areas and hot places of liquorrelated crime. Crime Prevention Studies 4: 145-184.

Boggess L, Maskaly J (2014) The spatial context of the disorder-crime relationship in a study of Reno neighborhoods. Social Science Research 43: 168-183.

Braga AA, Bond BJ (2008) Policing crime and disorder hot spots: A randomized controlled trial. Criminology 46: 577-607.

Braga AA, Papachristos AV, Hureau DM (2010) The concentration and stability of gun violence at micro places in Boston, 1980-2008. Journal of Quantitative Criminology 26: 33-53.

Braga AA, Papachristos AV, Hureau DM (2014) The effects of hot spots policing on crime: An updated systematic review and meta-analysis. Justice Quarterly 31: 633-663.

Braga AA, Weisburd DL, Waring EL, Mazerolle LG, Spelman W, Gajewski F (1999) Problemoriented policing in violent crime places: A randomized controlled experiment. Criminology 37: 541-580.

Brantingham PL, Brantingham PJ (1993) Nodes, paths and edges: Considerations on the complexity of crime and the physical environment. Journal of Environmental Pyschology 13: $3-28$.

Campello, RJGB, Moulavi D, Sander J (2013) Density-Based Clustering Based on Hierarchical Density Estimates. Proceedings of the 17th Pacific-Asia Conference on Knowledge Discovery in Databases, PAKDD 2013, Lecture Notes in Computer Science 7819: 160.

Caplan JM, Kennedy LW (2011) Risk terrain modelling: Brokering criminological theory and GIS methods for crime forecasting. Justice Quarterly 28: 360-381.

Chainey S, Thompson L, Uhlig S (2008) The utility of hotspot mapping for predicting spatial patterns of crime. Security Journal 21: 4-28.

Chappell A, Monk-Turner E, Payne B (2010). Broken windows or window breakers: The influence of physical and social disorder on quality of life. Justice Quarterly 28: 522-540.

Cohen MA, Piquero AR (2009) New evidence on the monetary value of saving a high risk youth. Journal of Quantitative Criminology 25: 25-49.

Curman, AS, Andresen MA, Brantingham PJ (2014) Crime and place: A longitudinal examination of street segment patterns in Vancouver, BC. Journal of Quantitative Criminology 31: 127-147. 
Curtis-Ham S, Walton D (2017) Mapping crime harm and priority locations in New Zealand: A comparison of spatial analysis methods. Applied Geography 86: 245-254.

Curtis-Ham S, Walton D (2018) The New Zealand crime harm index: Quantifying harm using sentencing data. Policing: A Journal of Policy and Practice 12: 455-467.

Deryol R, Wilcox P, Logan M, Wooldredge J (2016) Crime places in context: An illustration of the multilevel nature of hotspot development. Journal of Quantitative Criminology 32: 305-325.

Domínguez P, \& Raphael S (2015) The role of the cost-of-crime literature in bridging the gap between social science research and policy making: Potentials and limitations. Criminology \& Public Policy 14: 589-632.

Drawve G (2016) A metric comparison of predictive hot spot techniques and RTM. Justice Quarterly 33: 369-397.

Drawve G, Wooditch A (2019) A research note on the methodological and theoretical considerations for assessing crime forecasting accuracy with the predictive accuracy index. Journal of Criminal Justice Online First.

Eck JE, Chainey SP, Cameron JG, Leitner M, Wilson RE (2005) Mapping Crime: Understanding Hot Spots. USA: National Institute of Justice.

Eck JE, Clarke RV, Guerette RT (2007) Risky facilities: Crime concentration in homogenous setes of establishments and facilities. Crime Prevention Studies 21: 225-264.

Fenimore DM (2019) Mapping harmspots: An exploration of the spatial distribution of crime harm. Applied Geography 109: 102034.

Ferguson AG (2017) The rise of big data policing: Surveillance, race, and the future of law enforcement. New York: New York University Press

Flaxman S, Chirico M, Pereira P, Loeffler C (2019) Scalable high-resolution forecasting of sparse spatiotemporal events with kernel methods: a winning solution to the NIJ "realtime crime forecasting challenge". The Annals of Applied Statistics 13: 2564-2585.

Garnier S, Caplan JM, Kennedy LW (2018) Predicting dynamical crime distribution from environmental and social influences. Frontiers in Applied Mathematics and Statistics 4: 13.

Groff ER (2014) Quantifying the exposure of street segments to drinking places nearby. Journal of Quantitative Criminology 30: 527-548. 
Groff ER, Ratcliffe JH, Haberman CP, Sorg ET, Joyce NM, Taylor RB (2015) Does what police do at hot spots matter? The Philadelphia policing tactics experiment. Criminology 53: 2353.

Grubesic TH (2006) On the application of fuzzy clustering for crime hot spot detection. Journal of Quantitative Criminology 22: 77.

Haberman CP (2017) Overlapping hot spots? Examination of the spatial heterogeneity of hot spots of different crime types. Criminology \& Public Policy 16: 633-660.

Haberman CP, Stiver WH (2019) The Dayton foot patrol program: an evaluation of hot spots foot patrols in a central business district. Police Quarterly 22: 247-277.

Hahsler M, Piekenbrock M, Doran D (2019) dbscan: Fast Density-Based Clustering with R. Journal of Statistical Software 91: 1-30.

House PD, Neyroud PW (2018) Developing a crime harm index for Western Australia: The WACHI. Cambridge Journal of Evidence-Based Policing 2: 70-94.

Hunt PE, Anderson J, Saunders J (2017) The price of justice: new national and state-level estimates of the judicial and legal costs of crime to taxpayers. American Journal of Criminal Justice 42: 231-254.

Hunt PE, Saunders J, Kilmer B (2019) Estimates of law enforcement costs by crime type for benefit-cost analyses. Journal of Benefit-Cost Analysis 10: 95-123.

Ignatans D, Pease K (2016) Taking crime seriously: playing the weighting game. Policing: A Journal of Policy and Practice 10: 184-193.

Larson RC (1975) What happened to patrol operations in Kansas City? A review of the Kansas City preventive patrol experiment. Journal of Criminal Justice 3: 267-297.

Lee Y, Eck JE (2019) Comparing measures of the concentration of crime at places. Crime Prevention and Community Safety 21: 269-294.

Lee YJ, O SH, Eck JE (2019) A theory driven algorithms for real-time crime hot spot forecasting. Police Quarterly Online First.

Levine N (2008) The "Hottest" part of a hotspot: Commentary on "The utility of hotspot mapping for predicting spatial patterns of crime”. Security Journal 21: 295-302. 
Lum C, Koper CS, Telep CW (2011) The evidence-based policing matrix. Journal of Experimental Criminology 7: 3-26.

Macbeth E, Ariel B (2017) Place-based statistical versus clinical predictions of crime hot spots and harm locations in Northern Ireland. Justice Quarterly 36: 93-126.

Mitchell RJ (2019) The usefulness of a crime harm index: analyzing the Sacramento Hot Spot Experiment using the California Crime Harm Index (CA-CHI). Journal of Experimental Criminology 15: 103-113.

Mohler GO, Porter MD (2018) Rotational grid, PAI-maximizing crime forecasts. Statistical Analysis and Data Mining 11: 227-236.

Mohler GO, Short MB, Malinowski S., Johnson M., Tita GE, Bertozzi AL, Brantingham PJ (2015) Randomized controlled field trials of predictive policing. Journal of the American Statistical Association 110:1399-1411.

Norton S, Ariel B, Weinborn C, O’Dwyer E (2018) Spatiotemporal patterns and distributions of harm within street segments. Policing: An International Journal 41: 352-371.

O'Brien DT, Winship C (2017) The gains of greater granularity: The presence and persistence of problem properties in urban neighborhoods. Journal of Quantitative Criminology 33: 649-674.

Ratcliffe, JH (2015) Towards an index for harm-focused policing. Policing: A Journal of Policy and Practice 9: 164-182.

Ratcliffe JH, Sorg ET (2017) Foot patrol: rethinking the cornerstone of policing. Springer.

Ratcliffe JH, Taylor RB, Perenzin-Askey A, Thomas K, Grasso J, Bethel K, Fisher R, Koehnlein $\mathrm{J}$ (2020) The Philadelphia predictive policing experiment. Journal of Experimental Criminology Online First.

Ratcliffe JH, Taniguchi T, Groff ER, Wood JD (2011) The Philadelphia foot patrol experiment: A randomized controlled trial of police patrol effectiveness in violent crime hotspots. Criminology 49: 795-831.

Rosser G, Davies T, Bowers KJ, Johnson SD, Cheng T (2017) Predictive crime mapping: Arbitrary grids or street networks? Journal of Quantitative Criminology 33: 569-594.

Sherman LW, Gartin PR, Buerger ME (1989) Hot spots of predatory crime: Routine activities and the criminology of place. Criminology 27: 27-56 
Sherman LW, Neyroud PW, Neyroud E (2016) The Cambridge crime harm index: Measuring total harm from crime based on sentencing guidelines. Policing: A Journal of Policy and Practice 10: 171-183.

Sorg ET, Wood JD, Groff ER, Ratcliffe JH (2017) Explaining dosage diffusion during hot spot patrols: An application of optimal foraging theory to police officer behavior. Justice Quarterly 34: 1044-1068.

Taylor RB (2015) Community criminology: Fundamentals of spatial and temporal scaling, ecological indicators, and selectivity bias. NYU Press.

Van Patten I, McKeldin-Conor J, Cox D (2009) A microspatial analysis of robbery: Prospective hot spotting in a small city. Crime Mapping: A Journal of Research and Practice 1: 7-32.

Weinborn C, Ariel B, Sherman LW, O'Dwyer E (2017) Hotspots vs. harmspots: Shifting the focus from counts to harm in the criminology of place. Applied Geography 86: 226-244.

Weisburd D (2015) The law of crime concentration and the criminology of place. Criminology 53: 133-157.

Weisburd DL, Bushway SD, Lum C, Yang, SM (2004) Trajectories of crime at places: A longitudinal study of street segments in the city of Seattle. Criminology 42: 283-322

Wheeler AP (2019) Allocating police resources while limiting racial inequality. Justice Quarterly Online First.

Wheeler A, Gerell M, Yoo Y (2019) Testing the Spatial Accuracy of Address Based Geocoding for Gun Shot Locations. The Professional Geographer Online First.

Wheeler AP, Steenbeek W (2020) Mapping the risk terrain for crime using machine learning. https://osf.io/preprints/socarxiv/xc538/.

Wheeler AP, Worden RE, McLean SJ (2016) Replicating group-based trajectory models of crime at micro places in Albany, NY. Journal of Quantitative Criminology 32: 589-612.

Wolfgang M (1985) The National Survey of Crime Severity. Washington, D.C.: U.S. Department of Justice, Bureau of Justice Statistics.

Worrall JL, Wheeler AP (2019) Evaluating Community Prosecution Code Enforcement in Dallas, Texas. Justice Quarterly 36: 870-899. 




Figure 1: Historical hot spots used by the Dallas Police Department, Target Area Action Grid (TAAG) areas. 


\section{Based on Area}

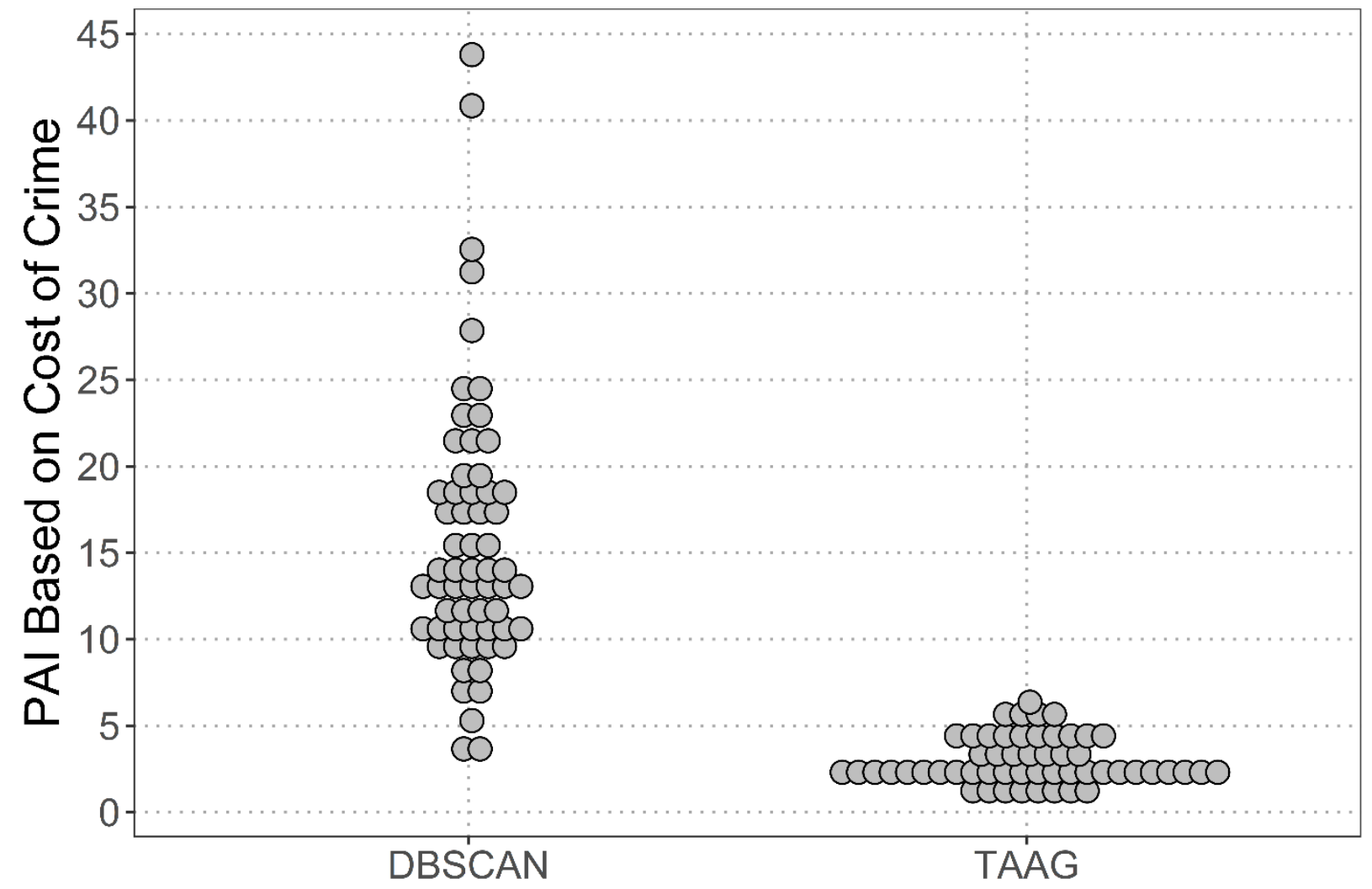

Figure 2: PAI statistics for individual DBSCAN crime harm weighted hotspots vs current TAAG areas. 


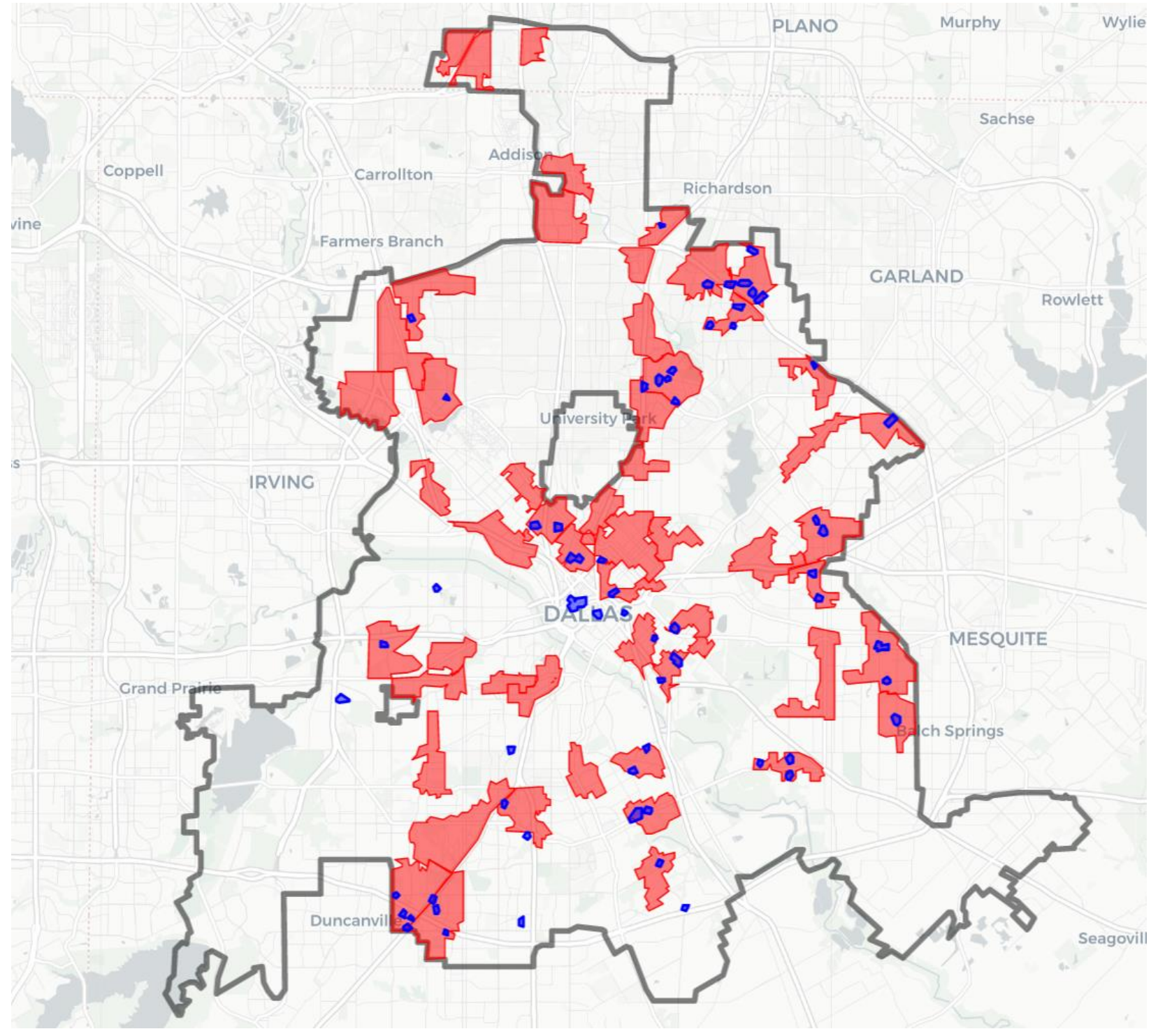

Figure 3: Screenshot of interactive map showing superimposed TAAG areas (red) with the constructed DBSCAN hot spot areas (Blue). Map available at https://apwheele.github.io/MathPosts/HotSpotMap.html. 


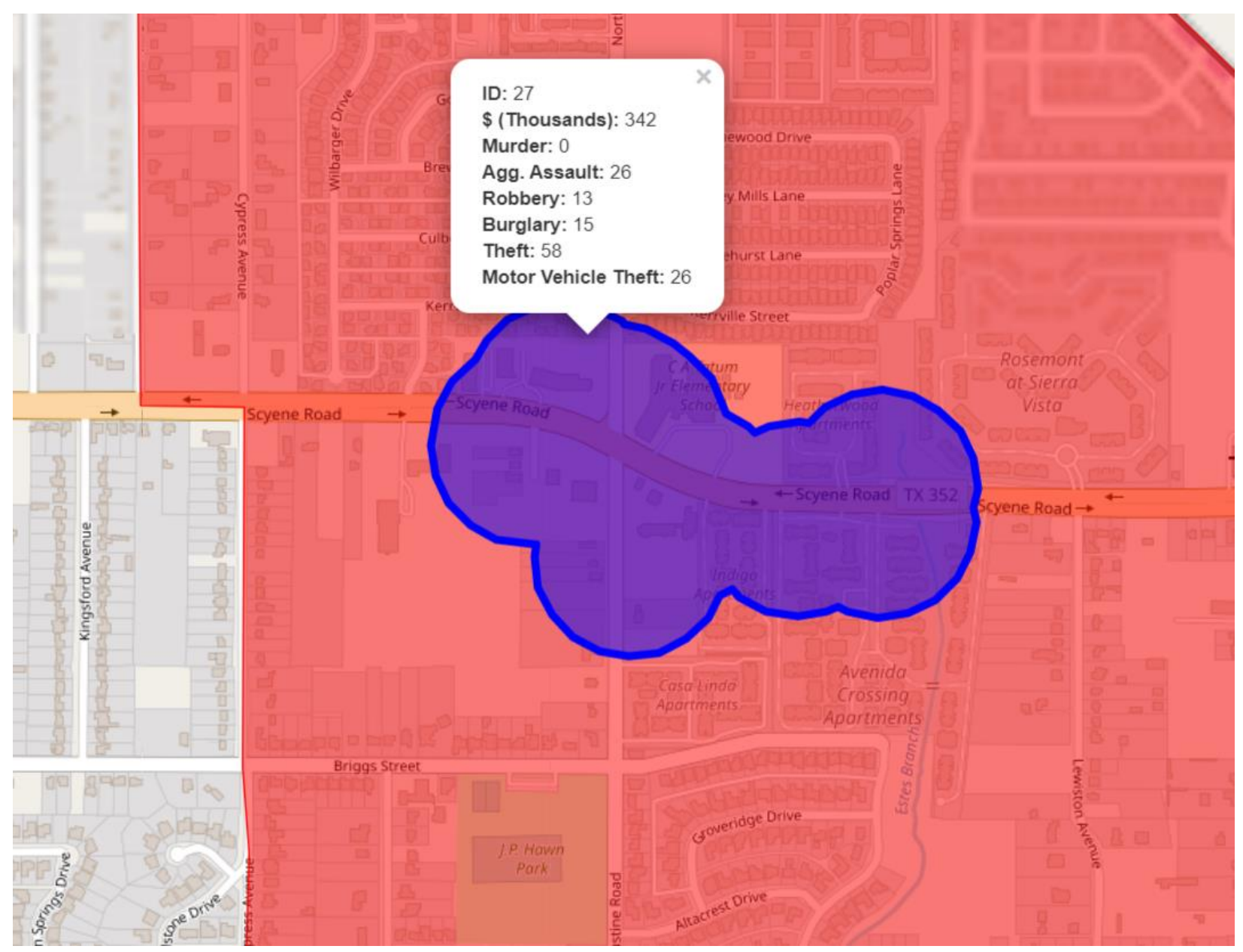

Figure 4: Zoomed in screenshot of interactive map showing superimposed TAAG areas (red) with the constructed DBSCAN hot spot areas (Blue). Blue DBSCAN areas have a textual description showing crime totals and harms totals for the individual area. Map available at https://apwheele.github.io/MathPosts/HotSpotMap.html. 
Table 1: Cost of Crime and Crime Totals

\begin{tabular}{lrrr} 
Crime & Cost of Crime & Training Totals & Test Totals \\
\hline Aggravated Assault & 8,292 & 17,485 & 9,864 \\
Burglary & 1,185 & 27,928 & 12,415 \\
Murder & 124,353 & 299 & 179 \\
Robbery & 2,229 & 9,879 & 4,932 \\
Theft & 1,024 & 63,159 & 31,134 \\
Motor Vehicle Theft & 769 & 18,209 & 10,029 \\
\hline
\end{tabular}

Table 2: Cumulative PAI statistics for DBSCAN areas vs TAAG areas

\begin{tabular}{|c|c|c|c|c|c|c|c|}
\hline & DBSCAN & \% Tot. DBSCAN & PAI DBSCAN & TAAG & \% Tot. TAAG & PAI TAAG & Citywide \\
\hline Total Harm (in Thousands) & 19,815 & $12 \%$ & 16.0 & 92,155 & $54 \%$ & 2.9 & 169,350 \\
\hline Aggravated Assault & 1,414 & $14 \%$ & 19.6 & 5,405 & $55 \%$ & 2.9 & 9,864 \\
\hline Burglary & 924 & $7 \%$ & 10.2 & 6,071 & $49 \%$ & 2.6 & 12,415 \\
\hline Murder & 20 & $11 \%$ & 15.3 & 106 & $59 \%$ & 3.1 & 179 \\
\hline Robbery & 631 & $13 \%$ & 17.5 & 3,018 & $61 \%$ & 3.2 & 4,932 \\
\hline Theft & 2,463 & $8 \%$ & 10.8 & 15,814 & $51 \%$ & 2.7 & 31,134 \\
\hline Motor Vehicle Theft & 753 & $8 \%$ & 10.3 & 5,254 & $52 \%$ & 2.8 & 10,029 \\
\hline Area (Square Miles) & 2.5 & $1 \%$ & & 65.0 & $19 \%$ & & 342 \\
\hline
\end{tabular}




\section{Appendix: PAI Statistics using Street Length instead of Area}

This appendix provides supplementary results when calculating PAI statistics using the street length contained within a hotspot instead of the area (Drawve \& Wooditch, 2019). They show comparable results. The cumulative citywide statistics show a smaller PAI totals for both the DBSCAN and TAAG areas, falling short of the PAI 10 ideal. However, when viewing individual hot spots identified, many have quite high weighted PAI statistics, and many of the TAAG areas overall are quite low.

\section{Based on Street Length}

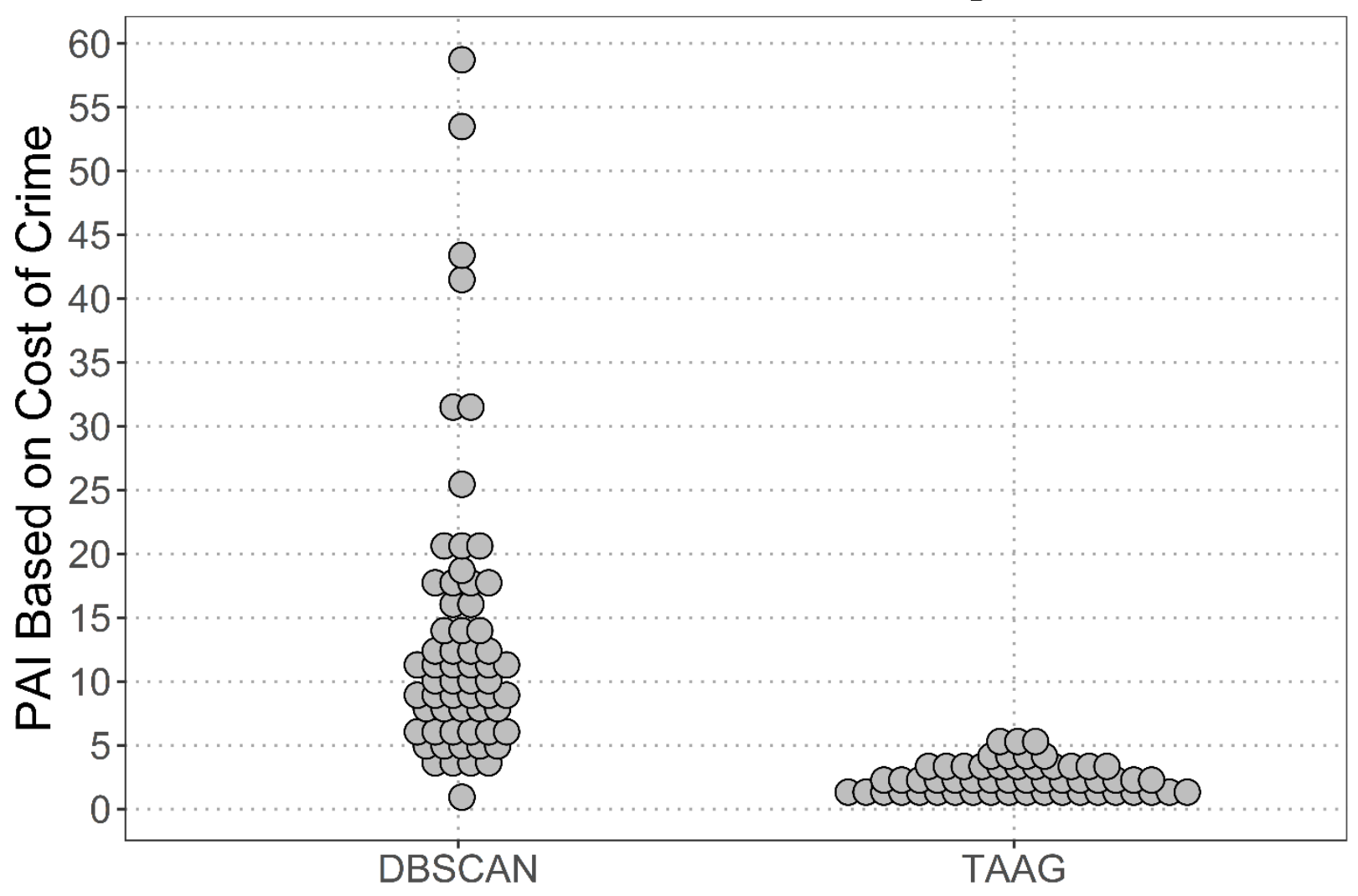

Figure A.1: PAI Statistics for Individual Hot Spot Areas, using the percent of weighted crime harm as the numerator, and the percent street length within a hot spot as the denominator. 
Table A.1: Cumulative Hot Spot Statistics, comparing PAI using area vs Street Length

\begin{tabular}{|c|c|c|c|c|c|c|c|c|c|}
\hline & DBSCAN & \% Tot DBSCAN & PAI DBSCAN (Area) & PAI DBSCAN (Len.) & TAAG & \% Tot TAAG & PAI TAAG (Area) & PAI TAAG (Len) & Total \\
\hline Total Harm (in Thousands) & 19,815 & $12 \%$ & 16.0 & 10.6 & 92,155 & $54 \%$ & 2.9 & 2.3 & 169,350 \\
\hline Aggravated Assault & 1,414 & $14 \%$ & 19.6 & 13.0 & 5,405 & $55 \%$ & 2.9 & 2.3 & 9,864 \\
\hline Burglary & 924 & $7 \%$ & 10.2 & 6.8 & 6,071 & $49 \%$ & 2.6 & 2.1 & 12,415 \\
\hline Murder & 20 & $11 \%$ & 15.3 & 10.1 & 106 & $59 \%$ & 3.1 & 2.5 & 179 \\
\hline Robbery & 631 & $13 \%$ & 17.5 & 11.6 & 3,018 & $61 \%$ & 3.2 & 2.6 & 4,932 \\
\hline Theft & 2,463 & $8 \%$ & 10.8 & 7.2 & 15,814 & $51 \%$ & 2.7 & 2.2 & 31,134 \\
\hline Motor Vehicle Theft & 753 & $8 \%$ & 10.3 & 6.8 & 5,254 & $52 \%$ & 2.8 & 2.2 & 10,029 \\
\hline Area (Square Miles) & 2.5 & $1 \%$ & & & 65.0 & $19 \%$ & & & 342 \\
\hline Length Streets (Miles) & 60.6 & $1 \%$ & & & $1,288.1$ & $23 \%$ & & & 5,498 \\
\hline
\end{tabular}

